\title{
Performance Measurement Systems for Craft-Oriented Small Enterprises
}

\author{
Inger Gamme ${ }^{1}$, Eva Amdahl Seim ${ }^{2}$, and Eirin Lodgaard ${ }^{3}$ \\ ${ }^{1}$ Gjøvik University College, Gjøvik, Norway \\ inger.gamme@hig.no \\ ${ }^{2}$ Norwegian University of Science and Technology, Trondheim, Norway \\ eva. amdahl. seimasintef. no \\ ${ }^{3}$ SINTEF Raufoss Manufacturing, Raufoss, Norway \\ eirin. lodgaardesintef.no
}

\begin{abstract}
Many leisure boat manufacturers have thrived on designing and building highly customized boats based on longstanding traditions of craftsmanship. The industry is to some extent moving towards the paradigm of "Mass Customization" in which the low cost of mass production is combined with customization.

Existing research on performance measurement systems (PMS), covers in little extent the implementation process and use of PMS in SMEs (small and medium sized enterprises). In this article, important elements for implementing a PMS and how it relates to creating a learning environment have been identified.
\end{abstract}

Keywords: SMEs, Performance Measurement System, Crafts man, Continuous Improvement.

\section{Introduction}

Craft oriented small enterprises make up the vast majority of SMEs in Europe, and contributes the main share of job creation in the European Union [1]. Furthermore, SMEs are shown to be important to the maintenance of a sustainable industrial economy, as they are assumed to be the main driving force in future economic growth in industrialized world economics. They often belong to the craft and artisan sector, and employ around one third of the total European workforce [2].

In an ever-changing environment, work conditions are becoming more complex, and what was considered good or core competence yesterday might not be so today. Competition in modern craft industries require craft manufacturers and their supply chains to innovate, improve, and increase their efficiency to meet the challenges from globalization and other forces for change [3]. The leisure boat industry is one example of an industry in which manufacturers are facing increased competition. In particular, the advance of industrialized leisure boat manufacturers is putting even high quality craft based "high end" manufacturers under strong competitive pressure. These manufacturers and their supply chains are now grappling with the challenge of how to meet 
this competitive pressure while preserving their unique quality of craft production [4]. A way for companies to deal with these dynamic and changing conditions could be to link strategies to overall objectives, to ensure a level of standardization. Although the importance of performance measurement is emphasized in the literature, it is rarely used in SMEs. Existing literature on performance measurement in SMEs does to a small extent capture the differences between using PMS in larger organizations versus using them in SMEs. However, after the realization that SMEs are not smaller versions of larger firms, but rather differed from larger firms in fundamental ways, the focus on management and performance measurement emerged [5]. The purpose of this paper is to contribute to a better understanding of the challenges in implementing a PMS in a craft-oriented small enterprise.

\section{Theory}

\subsection{Craft-Oriented SMEs}

Craft manufacturing still plays an important role in the economy. Principles and skills related to craft manufacturing has shown to be important for e.g. European economies to compete with new evolving economies. However, also craft manufacturing has to adapt to new manufacturing principles to be competitive. The focus on quality and time are critical to minimize waste, and obtain a high productivity performance level. As they deal with increased complexity in manufacturing, and some adoption of formalized managerial practice, PMS is especially important to support the required managerial development in order to meet market needs [6]. Moving from a craft oriented production to a more streamlined production with higher production volumes, requires more standardized processes and trained workers. The "knowledge stair" illustrates what is called an evolution of a "built to order" craft company into an industrialization process, where it is possible to lift the production step by step [7].

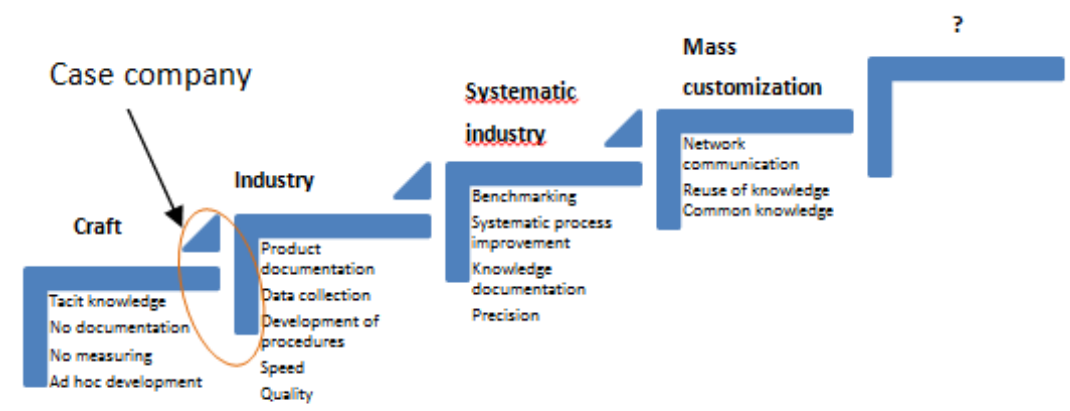

Fig. 1. Our company is currently in between the craft and industry level in the knowledge stairs presented by Svensson [7] 
'SMEs tend to have different needs and decision making process than larger firms [8]. Hence, operational processes seems to be more acknowledged than managerial processes, the organizational knowledge is mainly tacit, decision-making processes are poorly formalized and there is little understanding of the benefits of implementing a PMS. Craft oriented small enterprises are typically less formal organized with an ad hoc decision making structure [6]. Essential knowledge is often kept by few vital employees, which could be critical, especially in periods with high turnover of skilled workers [9]. To achieve organizational learning it is important to share tacit knowledge[10], and even though the SMEs may have a competitive advantage in being less bureaucratic and use of more informal communication than larger companies, it is also a need for more formal communication in the SMEs [11]. A study by Lovett [9] confirms that the information flow in SMEs mainly is informal, which could make it difficult for the management to get a complete overview of the use of knowledge and information within the organization. A way to improve the communication process, could be to use visual tools (like team boards), which means that every person involved must be able to see and understand different aspects of the process and its status at any time [12]. This will make the process more transparent and enabling feedback of current status [13]. Six basic mechanisms to integrate, or coordinate work in organizations are suggested: mutual adjustment, direct supervision, standardization of work, outputs, skills and norms. Mutual awareness enables individual workers to coordinate themselves by adjusting their own work to the work of others during the unfolding of activities and requires understanding of ongoing activities [14].

Larger companies often have more financial flexibility than small companies; and therefor easier could adjust to short time variations. Furthermore, SMEs tend to have a flat organization structure with few resources, which means that the same employees often have several job roles [15]. This shows the importance of using PMS to assure elements such as customer satisfaction, minimizing waste etc. even though the company has limited resources.

\subsection{Performance Measurement}

A PMS can be defined as "a system which is based on multi-dimensional performance measures that are derived from organization strategy with the purpose to implement the strategy, evaluate business performance, provide feedback and ensure communication, help in creating a learning environment and continuously improving the organization" [16]. Further, it can be illustrated as an instrument panel, which provides necessary information to enable employees at all levels of the organization to make the right decisions [17]. Most PMS's in use in SMEs today are of typical informal character, unstructured and mainly focusing on financial figures [15]. Additional research on "what can (not) be done in small organizations?" is required [18].

A resource effective PMS process is recommended, with short term benefits from the performance measures and also flexibility enough to cope with changes in strategy. This process focuses on establishing only one objective at a time with short term benefits, hence there will always be some measures fully implemented even though the implementation process stops after some iterations [15]. It is also important to put 
existing systems into an overall framework, and develop it together with additional new modules, when implementing new PMS. Occasionally generation of new systems without foundation and inter-linkage to overall system, should not be allowed [19]. Two drivers and four blockers can influence the success or failure of the implementation. The two driving factors are top management commitment and apprehended benefits from the process, while the four main obstacles are defined as: Lack of time and resources, insufficient access to necessary data, resistance to the PMS process and change of focus from parent company [20].

Many PMS implementation processes fail to succeed because the psychological effects of the PMS have not been taken into consideration. One of the most typical pitfalls is using measures on a personal level, where characters being measured can be tracked to one person. Finding excuses for poor performance figures, and therefore not striving to continuous improve them, could be other obstacles in achieving good performance system. There is also seen that the targets become the limit for continuous improvements; Organizations are satisfied when targets are reached, without aiming for further improvement [17]. To better cover the complete challenge that the companies face, there is a need for a more holistic system-based approach [5] [19].

\section{Method and Material}

\subsection{Introduction Case Company}

The case is a part of a larger research project where the main objective was to develop an effective, competitive and profitable production within leisure boat and craft oriented industry in Norway. The company is a craft oriented leisure boat producer with approximately 20 employees. The production line consists of three departments; molding, pre-assembly and assembly. The overall project period was from 2008 until 2012 , focusing on modularization and standardization of work processes. The challenge of the project has been to keep or improve the high quality level and customization that has characterized the craft manufacturing, but at the same time be more cost efficient. Furthermore, preservation of the craft tradition in addition to industrialization was emphasized to improve the competitive ability of the industry.

Even though the organization has made steps towards integration of its internal supply chain, it has a quite functional oriented structure, with several potentially builtin delays and inventories. There are very few formal reporting structures and systems, and those that exists are to a little extent process-oriented. However, there are a lot of contact and communication between the people in the manufacturing process and also between the technical resources in planning, problem solving etc. The manufacturing processes are mainly manually and adjustments are made all along the production process. There are few figures which are being measured today, and the main measure is "number boats produced per week". The quality of the manufactured boats is perceived by the market to be very high. Summarized, the company has several of the characteristics from the previously described craft manufacturing. 


\subsection{Data Collection}

We have used mixed methods with field and interview based studies among operators in the production line in a single craft oriented small enterprise. The researchers participated in project meetings at the leisure boat manufacturer in a research project aimed at improving their competitiveness. This included project board meetings, task meetings and workshops related to the projects. The interview session consisted of 12 in-depth interviews with operators from different process steps of the production line. A document analysis was carried out focusing on strategic documents. There were also performed a study of the measurement-, quality-, and planning systems. However, most of the time was spent at the shop floor together with the workers in action research. Action research is a valuable method where both researchers and professionals at a company collaborate to develop theory in the field. The action research cycle - diagnosing, planning, action, reflection, and evaluation of the results - was followed during the research [21].

\section{$4 \quad$ Findings and Discussion}

Current layout in the production line gives challenges in achieving transparency in the value chain. The production area is divided into sections where the operators are working in separate compartments which affect the information flow. The operators are not familiar with working in teams. Moving towards industrialization (knowledge stairs), it is necessary to formalize the information flow. To improve the transparency in the production area and create a learning environment with common arenas for information sharing and collaboration, team boards were introduced as the first step in a PMS implementation process. However, interviews and field studies revealed some resistance to this process.

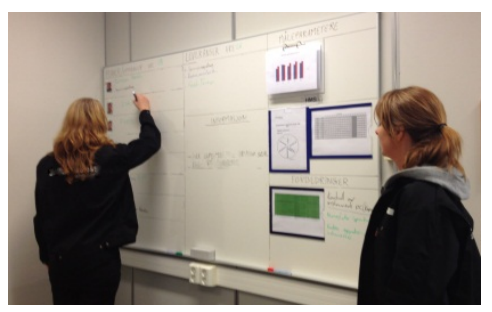

Fig. 2. Obtaining organizational learning through team boards

Three main issues have affected the PMS implementation process; (1) Lack of confidence in and compliance with established systems among the operators, (2) The operators do not see the need for any new system, and focus only upon their own process step and (3) Mainly single sourced information flow, and mostly linked through the foreman. 


\section{Lack of confidence in and compliance with established systems among operators:}

Through several expressions, an apparent overall lack of confidence in and compliance with established systems (production plans, process descriptions etc.) was revealed. As a part of the research project, several new systems were established, and one of these systems was a visual inventory control. The operators were responsible for the implementation process, and participated actively and apparently eagerly in this process, and seemed to be satisfied with the new system. However, the researchers became aware of incomplete or inconsistent compliance with the system and some operators even indicated that someone was sabotaging the new system.

Each operation had a satellite storage containing some of the smaller components, In addition to this; some operators also had their own additional safety stock, since they did not trust the storage system to secure supplies at all time. Some also indicated that the reliability of the system was dependent on which operator was responsible for the ordering process. The production plan was occasionally referred to as "not always correct". As compensation for the mistrust, the operators communicated the data orally. Some operators questioned if the reports produced at deviations were used for improvements at all, and could be seen as a tool for controlling and justifying, and to find out who is responsible when something goes wrong, instead of finding out what went wrong. Additionally some claimed that if deviations were too large, it would be hushed up, and no action would be taken.

\section{The operators do not see a need for any new system, and focus only upon their own}

process step: Although the standardization process had been going on for a while, a lack of ownership to the system was noticed. Several of the operators said they were satisfied with the current situation, and that any further improvements would only be experienced as superfluous workload, which fits in with Garengo's [6] observation, that one of the main obstacles when introducing PMS in SMEs, is the perception of PMSs as a bureaucratic an rigid system. The production people, with facilitation of the researchers, were given the authority to run the PMS process. However, some operators seemed to perceive the implementation process to be minor important, since the management did not directly participate, and therefore seemed to have focus on other issues.

The work load per operator is more difficult to identify when the production line is unorganized. Thus, an understanding of the inter-relationship between their processstep and other process steps could be lacking. In order to facilitate coordination among the workers, expedient approaches to information sharing and transparency seem necessary. The information was mainly informal, and to some extent occasionally who got the information. This shows the importance of information coordination in order to create a learning environment[16]. The operators trust the foremen to give them the needed information, and they feel that further information was not necessary. 


\section{Mainly single sourced information flow, and often linked through the foreman:}

The foremen are the main sources for both the horizontal and the vertical information flow. Information sharing through meetings or arenas for information sharing such as team boards etc. was among some operators considered as superfluous. Some of them commented: "It is not necessary; we just go and talk to each other".

Between the operators it seemed to be a mutual adjustment mechanism, whereby two or more people equally adapt to each other, usually by informal communication, in order to flexible handle unexpected happenings [14]. Coordination between the foreman and the operators consist of direct supervision, where the foreman is the responsible for coordinating the work. There is also a risk that the foreman becomes a bottleneck in coordination and information sharing, when verbatim work coordination is the only solution.

\section{Conclusion}

Based on the case study, it has been shown that there exist different challenges when implementing a PMS. The experiences from this case study indicate the importance of finding the correct degree of implementation of a PMS which fits this type of organization. When an organization establishes a new system such as PM, it must be considered how to proceed for the implementation phase to achieve successful integration. First, we recommend putting management commitment to PMS as the base or foundation. Once the foundation is in place, attention should be given to the implementation process and how to proceed. Without the management commitment and direct involvement in the implementation process the usefulness of the PMS is expected to be limited. Resistance towards implementation of new systems among the operators must also be taken into consideration. One way to reduce this resistance could be to ensure that the employees actively participate in the implementation process, which further could contribute to a better confidence and compliance with new systems. Although operators themselves are highly skilled, collaboration with the management function is important to develop a common understanding of the impact and the need of a PMS, and also ensure the linkage towards the overall strategy.

Literature indicates that use of team boards may be valuable to formalize information flows and collaboration between management and workers. Based on the findings from our research, we find this type of tool helpful to strengthen both the horizontal and vertical communication and information flow. Furthermore it can contribute to reveal tacit knowledge and increase organizational transparency, and through visual follow-up ensure the success of the PMS implementation process.

\section{References}

1. Buschfeld, D., Dilger, B., Hess, L., Schmid, K., Voss, E.: Identification of Future Skills Needs in Micro and Craft (-type) Enterprises up to 2020. Final report, Cologne, Hamburg, Vienna (January 2011)

2. de Vries, H., Margaret, J.: The Development of a Model to Assess the Strategic Management Capability of Small- and Medium-Size Businesses. Journal of American Academy of Business 3, 85-85 (2003) 
3. O’Sullivan, D., Rolstadås, A., Filos, E.: Global Education in Manufacturing Strategy. Journal of Intelligent Manufacturing 22, 663-674 (2011)

4. Økland, A., Lillebo, B., Amdahl, E., Seim, A.: A Framework for Transparency. In: POMS 21st Annual Conference, Vancouver, Canada (2010)

5. Bititci, U., et al.: Performance Measurement: Challenges for Tomorrow. International Journal of Management Reviews (2011)

6. Garengo, P., Biazzo, S., Bititci, U.S.: Performance Measurement Systems in SMEs: A review for a Research Agenda. International Journal of Management Reviews 7, 25-47 (2005)

7. Svensson, C., Barfod, A.: Limits and Opportunities in Mass Customization for "Build to Order" SMEs. Computers in Industry 49, 77-89 (2002)

8. Shrader, C.B., Mulford, C.L., Blackburn, V.L.: Strategic and Operational Planning, Uncertainty, and Performance in Small Firms. Journal of Small Business Management 27, 45-45 (1989)

9. Lovett, P.J., Ingram, A., Bancroft, C.N.: Knowledge-Based Engineering for SMEs - a Methodology. Journal of Materials Processing Technology 107, 384-389 (2000)

10. Nonaka, I., Takeuchi, H.: The Knowledge-Creating Company. Oxford University Press, New York (1995)

11. Vinten, G.: Corporate Communications In Small- and Medium-Sized Enterprises. Industrial and Commercial Training 31, 112-119 (1999)

12. Parry, G.C., Turner, C.E.: Application of Lean Visual Process Management Tools. Production Planning \& Control 17, 77-86 (2006)

13. Womack, J.P., Jones, D.T.: Lean Thinking: Banish Waste and Create Wealth for Your Corporation. Simon \& Schuster, New York (1996)

14. Glouberman, S., Mintzberg, H.: Managing the Care of Health and the Cure of DiseasePart II: Integration. Health Care Management Review 26, 56-69 (2001)

15. Hudson, M., Lean, J., Smart, P.A.: Improving Control through Effective Performance Measurement in SMEs. Production Planning \& Control 12, 804-813 (2001)

16. Khan, K., Shah, A.: Understanding Performance Measurement Through the Literature. African Journal of Business Management 5, 13410-13418 (2011)

17. Andersen, B., Fagerhaug, T.: Performance Measurement Explained - Designing and Implementing Your State-of-the-Art System. American Society for Quality, Milwaukee (2001)

18. Van Dooren, W.: What Makes Organisations Measure? Hypotheses on the Causes and Conditions for Performance Measurement. Financial Accountability \& Management 21, 363-383 (2005)

19. Andersen, B., Henriksen, B., Aarseth, W.: Holistic Performance Management: an Integrated Framework. International Journal of Productivity and Performance Management 55, 61-78 (2006)

20. Mike Bourne, J., et al.: Designing, Implementing and Updating Performance Measurement systems. Emerald Group Publishing 20, 754-771 (2000)

21. Karlsson, C.: Researching Operations Management. Routledge, New York (2009) 